\title{
The pseudo-acoustic equations of the scalar wavefield in anisotropic media
}

\begin{abstract}
In this paper we present a new formulation of scalar pseudo-acoustic wave equation in arbitrary anisotropic media TI (Transverse Isotropy) type for 2D and 3D cases. These equations, based on precise dispersion relation, determine eigenvalue - temporal frequency as the function of wavenumber and anisotropy parameters. Here we present a few snapshots obtained for different signals by one-way equation.
\end{abstract}

Key words: forward modelling, TI, Transverse Isotropy, pseudo-acoustic equation, one-way equation, dispersion relation.

\section{Pseudoakustyczne równanie skalarnego pola falowego w ośrodkach anizotropowych}

W artykule przedstawiono nowe sformułowanie skalarnych pseudospektralnych równań falowych w dowolnych ośrodkach anizotropowych typu TI (Transverse Isotropy) dla przypadków 2D i 3D. Równania bazują na dyspersyjnych relacjach wyznaczających wartości własne - częstotliwości w funkcji liczb falowych i parametrów anizotropii na podstawie pełnego systemu równań akustycznych. Zaprezentowano kilka przypadków propagacji falowej określonej jednostronnym równaniem w formie migawkowych zdjęć dla różnych typów sygnału.

Słowa kluczowe: anizotropia, poprzeczna izotropia (TI), modelowanie, jednostronne równanie falowe, relacja dyspersyjna.

\section{Introduction}

Forward modelling of seismic waves in anisotropic media should be executed by solving a full system of elastic wave equations using numerical techniques such as finite-difference, spectral and pseudo-spectral method $[3,7,9,10,11,17,19$, $20,23]$. Due to the very time-consuming calculation system of modelling three component acoustic field and insufficient data concerning elastic parameters, in practical seismic research the tendency to simplify the theory and to limit oneself to the considerations of a few models of anisotropy can be noted.
Alkhalifah T. [1, 2] introduced for $P$ (compressional) wave fourth-order pseudo-acoustic scalar equations in the space-time domain. In this equation for vertical transverse isotropy (VTI) shear wave velocity $V_{S}=0$ is assumed. Alkhalifah's approximation was an inspiration for many studies [4-6, 21, 22].

In this paper, we present pseudo-acoustic wave equations, first and second order, versus time in the wavenumbers domain for transverse isotropic media (TI). Some numerical examples were presented as snapshots of propagating wavefields.

\section{Dispersion relations}

Let us consider the TTI (Tilted Transverse Isotropy) model in which the plane of symmetry is dipping at angle $\theta$ versus the horizontal XOY plane, and the symmetry axis lies in the $X O Z$ plane, i.e. in the plane of acquisition. This model is the starting point for other models of transverse isotropy, i.e. for VTI (Vertical Transverse Isotropy) and HTI (Horizontal Transverse Isotropy) for azimuthal angle accordingly $\Psi=90^{\circ}$ and $\theta=90^{\circ}$. In this case, deriving eigenvalue $\omega_{a}$ - temporal frequency from the full system of elastic equations, we obtain [13]: 


$$
\omega_{a}^{4}-\omega_{a}^{2} F( \pm)+G( \pm)=0
$$

The solution of the biquadratic equation (1) for upgoing waves is the following:

$$
\omega_{a}=\frac{1}{\sqrt{2}}\left\{F( \pm)+\left[F^{2}( \pm)-4 G( \pm)\right]^{1 / 2}\right\}^{1 / 2}
$$

where

$$
\begin{aligned}
F( \pm)= & \left(d_{11}+d_{55}\right) k_{x}^{2}+( \pm) 2 k_{x} k_{z}\left(d_{15}+d_{35}\right)+\left(d_{33}+d_{55}\right) k_{z}^{2} \\
G( \pm)= & \left(d_{11} d_{55}-d_{15}^{2}\right) k_{x}^{4}+( \pm) 2 k_{x}^{3} k_{z}\left(d_{35} d_{11}-d_{15} d_{31}\right)+ \\
& +\left[d_{11} d_{33}+2\left(d_{15} d_{35}-d_{13} d_{55}\right)-d_{13}^{2}\right] k_{x}^{2} k_{z}^{2}+ \\
& +( \pm) 2 k_{x} k_{z}^{3}\left(d_{15} d_{33}-d_{35} d_{13}\right)+\left(d_{55} d_{33}-d_{53}^{2}\right) k_{z}^{4}
\end{aligned}
$$

In the formulas (3) the sign (+) refers to acquisition moving along the $X$ axis in the positive direction of the axis, i.e. "dip down"; while the sign (-) refers to the "dip-up" direction. In relation (3) $d_{i j}$ are components of elastic tensor $D^{\theta . \Psi=90^{\circ}}$ for azimuthal angle $\Psi=90^{\circ}$ [15].

From the relation (1-3) with the assumption that velocity of shear wave $V_{S V}=0$ we obtain for VTI $\left(\theta=0^{\circ}\right)$ and HTI $\left(\theta=90^{\circ}\right)$ models the following equations:

$$
\begin{aligned}
& F_{V T I}=V_{p z}^{2}\left(q k_{x}^{2}+k_{z}^{2}\right) \\
& G_{V T I}=V_{p z}^{4} \eta_{a} k_{x}^{2} k_{z}^{2}
\end{aligned}
$$

and

$$
\begin{aligned}
& F_{H T I}=V_{p x}^{2}\left(k_{x}^{2}+q k_{z}^{2}\right) \\
& G_{H T I}=V_{p x}^{4} \eta_{a} k_{x}^{2} k_{z}^{2}
\end{aligned}
$$

In relations (4-5) the compressional velocity $V_{p z}$ and $V_{p x}$ mean velocities in perpendicular directions to symmetry planes, i.e. to the $X Y$ plane for the VTI model and to the $Z Y$ plane for the HTI model, $q=1+2 \varepsilon$ and $\eta_{a}=2(\varepsilon-\delta)$, where $\varepsilon$ and $\delta$ are Thomsen's [18] parameters and $k_{x}, k_{z}$ are wavenumbers.

Generally, the equation (1) can be obtained in the 2-dimensional case as the result of matrix equation solving:

$$
\left[\begin{array}{ll}
a_{11} & a_{12} \\
a_{21} & a_{22}
\end{array}\right]\left[\begin{array}{l}
U_{x} \\
U_{z}
\end{array}\right]=0
$$

where the elements of symmetrical matrix $\left[a_{i k}\right]$ are functions of wavenumbers $k_{x}, k_{z}$, Thomsen's parameters and angles: $\theta, \Psi, U_{x}$ and $U_{z}$ are components of the displacement. Equation (6) means that component $U_{y}$ does not exist in the first and second lines of the matrix, which was constructed according to Hooke's Law, and can be solved by the calculation of the determinant of the matrix (6).

The precondition for the determination of the two dimensionality of wavefield $\frac{\partial U_{y}}{\partial y}=0$ does not eliminate the component $U_{y}$.
If the component $U_{y}$ arises in each line of the matrix, then we have the determinant of the third order matrix.

$$
\left[\begin{array}{lll}
a_{11} & a_{12} & a_{13} \\
a_{21} & a_{22} & a_{23} \\
a_{31} & a_{32} & a_{33}
\end{array}\right]\left[\begin{array}{l}
U_{x} \\
U_{y} \\
U_{z}
\end{array}\right]=0
$$

In this case, the eigenvalue of equation (7), i.e. temporal frequency $\omega_{a}$ is expressed by an algebraic equation of the sixth order. This is a consequence of the fact that in elements $a_{11}$, $a_{22}, a_{33}$ of matrix (7) quadric frequency $\omega_{a}$ remains.

This allows the reduction of the equation to a form named Cardano's equation:

$$
y^{3}-B y^{2}+C y-H=0
$$

If we assume

$$
\omega_{a}^{2}=y=x+\frac{1}{3} B
$$

then the equation (8) takes the form

$$
x^{3}+x l_{1}+l_{2}=0
$$

Cardano's solution of the equation (10) has the form

$$
\begin{aligned}
x= & {\left[-\frac{1}{2} l_{2}+\left(\frac{1}{4} l_{2}^{2}+\frac{1}{27} l_{1}^{3}\right)^{1 / 2}\right]^{1 / 3}+} \\
& +\left[-\frac{1}{2} l_{2}-\left(\frac{1}{4} l_{2}^{2}+\frac{1}{27} l_{1}^{3}\right)^{1 / 2}\right]^{1 / 3}
\end{aligned}
$$

where

$$
l_{1}=C-\frac{1}{3} B^{2} \text { and } l_{2}=\frac{1}{3} B C-\frac{2}{27} B^{3}-H
$$

$B=k_{x}^{2}\left(d_{11}+d_{66}\right)+k_{z}^{2} d_{33}$

$C=k_{x}^{2} k_{z}^{2}\left(d_{11} d_{33}+d_{66} d_{33}-d_{63}^{2}-d_{13}^{2}\right)+k_{x}^{4}\left(d_{11} d_{66}-d_{16}^{2}\right)$

$H=k_{x}^{4} k_{z}^{2}\left[d_{11}\left(d_{33} d_{66}-d_{63}^{2}\right)-d_{16}^{2} d_{33}+d_{13} d_{16} d_{66}-d_{13}^{2} d_{66}\right]$

Taking in considerations that each component of the $d_{i j}$ elasticity tensor contains squared velocity $V_{P}^{2}$ in a perpendicular direction to the isotropy plane, and considering the structure of relations (2-3) and (11-12), we can easily notice that the relation

$$
\frac{\omega_{a}^{2}}{V_{\mathrm{p}}^{2}}=k_{a}^{2}\left(k_{x}, k_{z}, \theta, \Psi, \varepsilon, \delta\right)
$$

is valid (stands) for 2D and 3D dimensional cases [equation (7)].

In equation (13) $k_{a}^{2}$ corresponds to the function of vector wave components, angles $\theta$ and $\Psi$ Thomsen's parameters ( $\varepsilon$ and $\delta$ ), and is the solution of equation (2) for the 2D case and the solution of equation (11) for the $3 \mathrm{D}$ case, where the separation of velocity $V_{p}$ was used.

From (13), by multiplying both sides by the scalar $P\left(k_{x}\right.$, $\left.k_{y}, k_{z}, \omega_{a}\right)$ in wavenumbers $\left(k_{x}, k_{z}\right)$ - frequencies $\omega_{a}$ domain and after applying inverse Fourier $(\omega \rightarrow t)$ we obtain 


$$
\frac{1}{V_{p}^{2}} \frac{\partial^{2} P\left(k_{x}, k_{z}, t\right)}{\partial t^{2}}=-k_{a}^{2} P\left(k_{x}, k_{z}, t\right)
$$

i.e. the two-way equation named pseudo-acoustic.

From (14) we have

$$
\frac{\partial P\left(k_{x}, k_{z}, t\right)}{\partial t}= \pm i V_{\mathrm{P}} k_{a} P\left(k_{x}, k_{z}, t\right)
$$

i.e. the one-way equation wavefield.

The direction of propagation is fixed by the sign of temporal frequency $\omega_{a}$. In the Cartesian system of coordinates with the $Z$ axis directed "down" and representing depth of medium, sign $(+)$ in relation (15) describes the upcoming wave towards $z=0$.

Generally, the solution of equation (14) is the relation expressed by the Fourier transform:

$P(x, y, z, t)=$

$=\sum_{k_{x}} \sum_{k_{y}} \sum_{k_{z}} P\left(k_{x}, k_{y}, k_{z}, t=0\right) \exp \left[i\left(k_{x} x+k_{y} y+k_{z} z \pm \omega_{a} t\right)\right]$

In heterogeneous anisotropic media, equation (15) should be replaced by the spectral form, and then we have:

$$
\frac{\partial P(x, y, z, t)}{\partial t}=i V_{p}(x, y, z) F^{-1}\left\{k_{a} F[P(x, y, z, t)]\right\}
$$

where $F\left(x \rightarrow k_{x}, y \rightarrow k_{y}, z \rightarrow k_{z}\right)$ and $F^{-1}\left(x \rightarrow k_{x}, y \rightarrow k_{y}\right.$, $z \rightarrow k_{z}$ ) are operators representing the Fourier transform from the $(x, y, z)$ domain to the $\left(k_{x}, k_{y}, k_{z}\right)$ domain, and vice versa.

The sought after wavefield in time $t=\Delta t$ can be approximated by the truncated (three derivatives) Taylor's series for $t=0$ :

$$
P(x, y, z, \Delta t)=\sum_{n=0}^{3} \frac{\partial^{n} P(x, y, z, t=0)}{\partial t^{n}} \frac{\Delta t^{n}}{n !}
$$

This third-order scheme is stable in the isotropic case [8]. The assumed seismic signal at time $t=0$ is the initial wavefield, whereas its first derivative at time $t=0$ is expressed by equation (17).

The second and third derivatives are expressed as follows:

$$
\begin{gathered}
\frac{\partial^{2} p(x, y, z, t)}{\partial t^{2}}=-V_{p}^{2}(x, y, z) F^{-1}\left\{k_{a}^{2} F[p(x, y, z, t)]\right\} \\
\frac{\partial^{3} p(x, y, z, t)}{\partial t^{3}}=-i V_{p}^{3}(x, y, z) F^{-1}\left\{k_{a}^{3} F[p(x, y, z, t)]\right\}
\end{gathered}
$$

Relations (16) and (17-20) define process of wave propagation in the determined direction in anisotropic media.

According to Loventhal's et al [16] conception of simultaneously excited seismic reflectors, the zero-offset time section can be obtained when a half velocity $1 / 2 V_{p}$ is accepted as the velocity of wavefield propagation. The construction of zero-offset sections is based on the principle of addition waves recorded on $z=0[13,14]$. The principle advantage of the one-way equation application is the elimination of multiples.

Generally, the time section for arbitrary offset can be obtained using the second order wave equation described by relation (14). Then, we use time differencing schema for the finite expression of the second order time derivative. However, all space derivative terms are evaluated by using Fourier transform methods.

\section{Testing}

To verify the correctness of wave propagation in media with different properties of anisotropy some numerical experiments using one-way equation (17) and Taylor's relations (18-20) were made. The main aim of those experiments was the estimation of the usefulness of the applied signals. In experiments were assumed anisotropic medium HTJ with Thomsen's parameters: $\varepsilon=0.3$ and $\delta=0.1$; velocity of compressional wave $V_{p}=2000 \mathrm{~m} / \mathrm{s}$ (in perpendicular direction to plane isotropy).

The exited signal is set in a point with coordinates: $x=6000 \mathrm{~m}, z=2400 \mathrm{~m}$. We used tree signals: Ricker's $60 \mathrm{~Hz}$ signal, and two signals shown in Fig. 1: the zero-phase signal and a signal in spike form. In Fig. 2 a snapshot of the propagated Ricker's signal for time $t=0.2 \mathrm{~s}$ is shown.

The circle forming the wave front is caused by the accepted azimuthal angle $\Psi=0^{\circ}$, which means that propagation in the $X O Z$ plane is made in the isotropic plane. The image

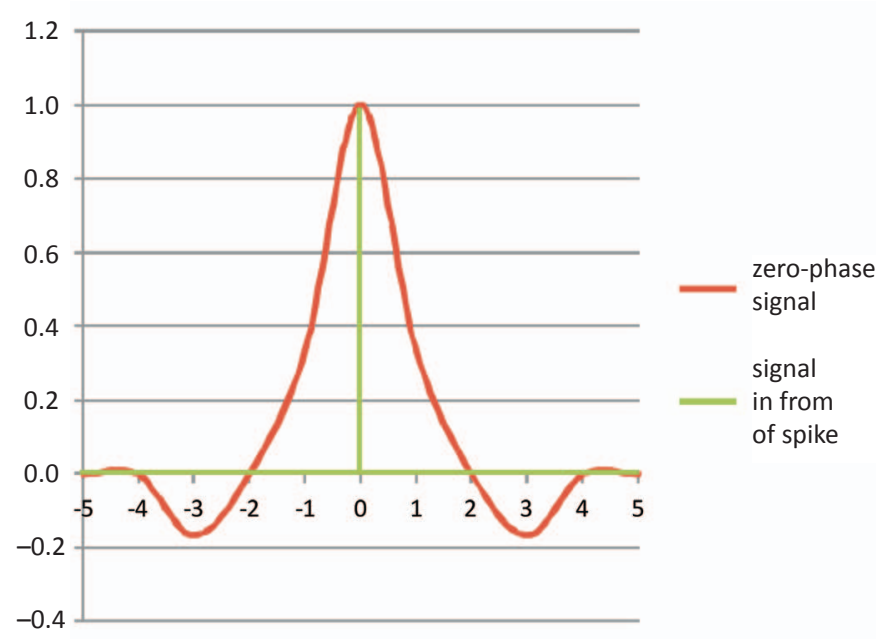

Fig. 1 The signals which were used for numerical experiments - a), zero-phase signal - b), signal in the form of a spike 
of the wavefront is distorted by random noise. For these same parameters of HTI media with azimuthal range $\Psi=0^{\circ}$ and for zero-phase signal a snapshot was obtained, which is kinematically similar (Fig. 3) to the result in Fig. 2.

Without any doubt, better resolution is observed when we use the signal in spike form (Fig. 4).

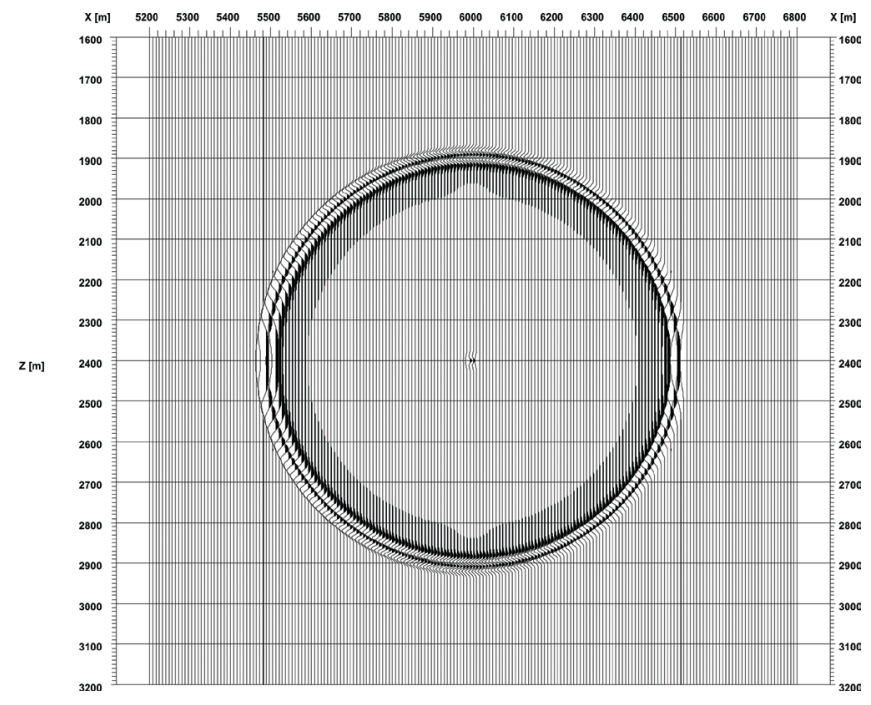

Fig. 2. A snapshot of Ricker's $60 \mathrm{~Hz}$ signal propagation for time $\Delta t=0.2 \mathrm{~s}$ and for $\varepsilon=0.3, \delta=0.1$; azimuthal angle $\Psi=0^{\circ}$. Steps of calculations: $\Delta x=\Delta z=0.4 \mathrm{~m}, \Delta t=0.5 \mathrm{~ms}$

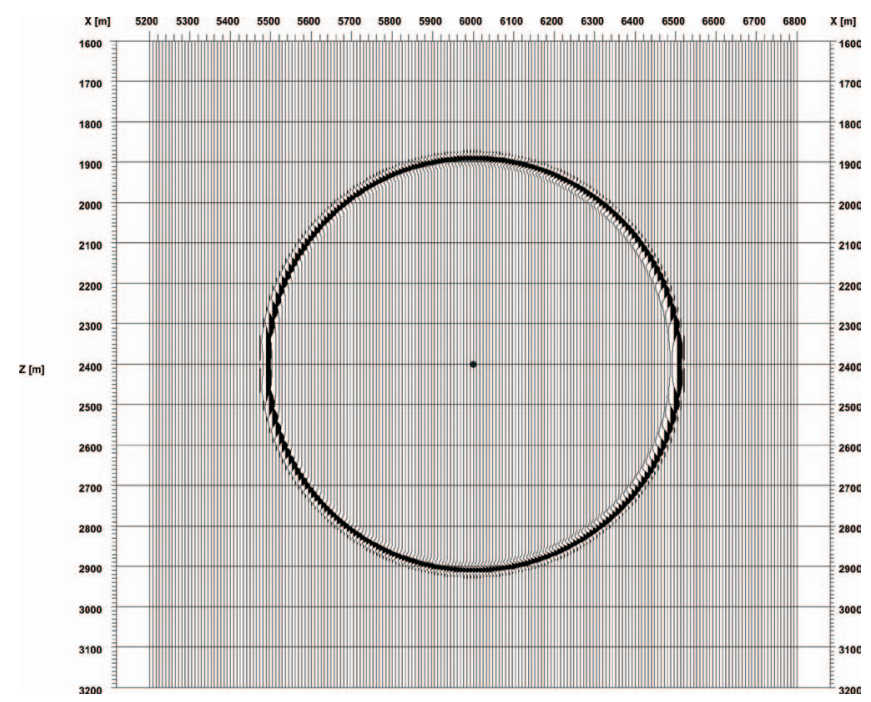

Fig. 4. A snapshot of spike signal propagation for time $\Delta t=0.2 \mathrm{~s}$ and for $\varepsilon=0.3, \delta=0.1$; azimuthal angle $\Psi=0^{\circ}$.

Steps of calculations: $\Delta x=\Delta z=0.4 \mathrm{~m}, \Delta t=0.5 \mathrm{~ms}$
In Fig. 5 we present a snapshot of the signal in spike form propagation in HTI media with parameters: $\varepsilon=0.3$, $\delta=0.2, \Psi=15^{\circ}$.

In this case, we can observe a changed form of wavefront, which is now ellipsoidal. Numerical experiments were made with steps: $\Delta x=\Delta z=4 \mathrm{~m} ; \Delta t=0.5 \mathrm{~ms}$.

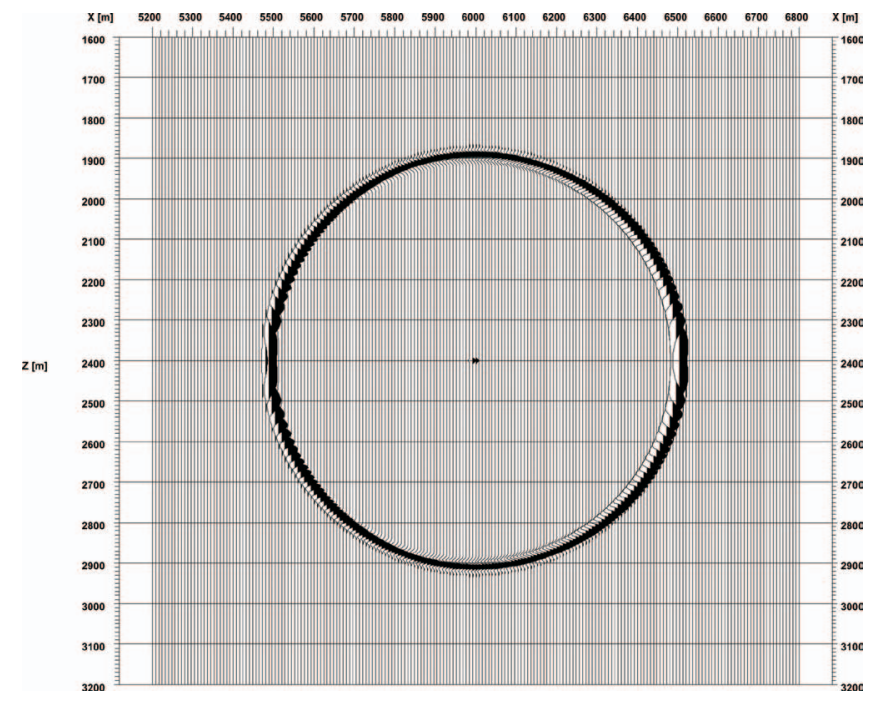

Fig. 3. A snapshot of zero-phase signal propagation for time $\Delta t=0.2 \mathrm{~s}$ and for $\varepsilon=0.3, \delta=0.1$; azimuthal angle $\Psi=0^{\circ}$.

Steps of calculations: $\Delta x=\Delta z=0.4 \mathrm{~m}, \Delta t=0.5 \mathrm{~ms}$

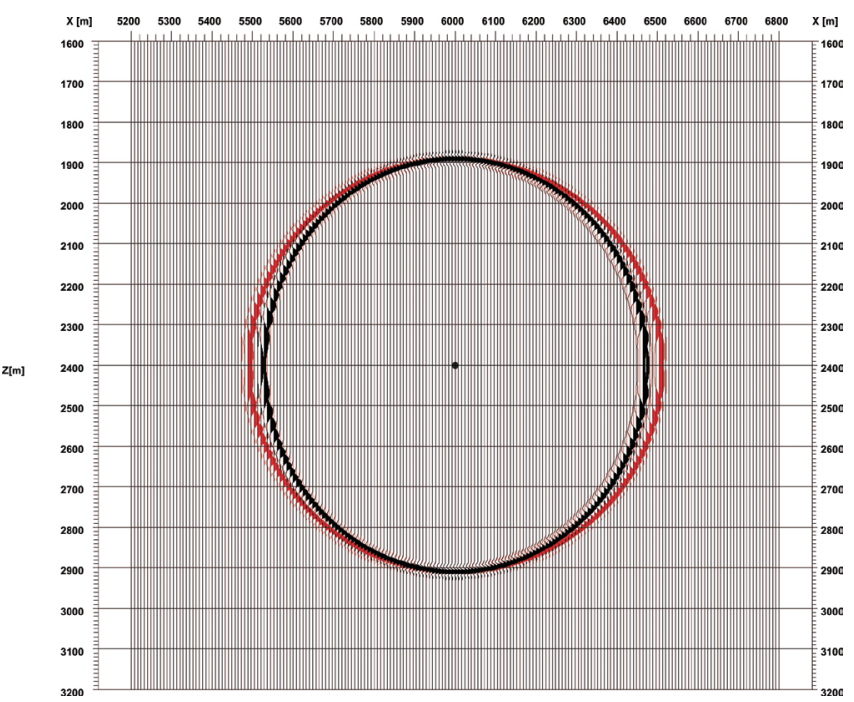

Fig. 5. The comparison of snapshots of spike signal propagation for $\varepsilon=0.3, \delta=0.1$; azimuthal angle $\Psi=0^{\circ}$ (in red) and $\Psi=30^{\circ}$

\section{Discussion and conclusions}

Here, we have presented some examples of wave propagation in $\operatorname{HTJ}(\Psi)$ as a function of azimuthal angle $\Psi$ based on a one-way equation in the wavenumber frequency domain. In order to obtain the images of propagation waves for both directions $( \pm \omega)$ one should make separate calculations for the propagation wave into $z=0$ and in the opposite direction and then stick to those images. In this way we created the circumstance to use one way equation without multiples in reflection seismic models.

To sum up, in this work:

- generalized pseudo acoustic equations (shear velocity $V_{s}=0$ ) in anisotropic media for arbitrary transverse isotropy 
(TI) in 2D and $3 \mathrm{D}$ cases in the frequency-wavenumbers domain were formulated,
- the kinematical correctness in snapshots of wave propagation for the considered 2D models was demonstrated.

Please cite as: Nafta-Gaz 2015, no. 11, pp. 811-815, DOI: 10.18668/NG2015.11.01

Article contributed to the Editor 5.08.2015 r. Approved for publication 20.10.2015 r.

The article is the result of research conducted in connection with a project: Seismic tests and their application in detection of shale gas zones. Selection of optimal parameters for acquisition and processing in order to reproduce the structure and distribution of petrophysical and geomechanical parameters of prospective rocks, as part of the programme BLUE GAS - POLISH SHALE GAS. Contract No. BG1/GASLUPSEJSM/13.

\section{Literature}

[1] Alkhalifah T.: Acoustic approximation for processing in transversely isotropic media. Geophysics 1998, vol. 63, pp. 623-631.

[2] Alkhalifah T.: An acoustic wave equation for anisotropic media. Geophysics 2000, vol. 65, pp. 1239-1250.

[3] Danek T., Lesniak A., Pieta A.: Numerical modeling of seismic wave propagating in selected anisotropic media. Studia, Rozprawy, Monografie Nr 16, Instytut Gospodarki Surowcami Mineralnymi i Energią PAN 2010.

[4] Du X., Fletcher R., Fowler P. J.: A new pseudo-acoustic wave equation for TI media. $70^{\text {th }}$ Annual International Conference and Exhibition, EAGE, Extended Abstracts, H033, 2008.

[5] Duveneck E., Bakker P. M.: Stable P-wave modeling for reverse time migration in tilted media. Geophysics 2011, 76, no. 2, pp. 565-575, DOI: 10.1190/1.3533964.

[6] Fletcher R., Du X., Fowler P.: Reverse time migration in tilted transversely isotropic (TTI) media. Geophysics 2009, vol. 74, WCA179-WCA187.

[7] Fornberg B.: The pseudospectral method. Comparisons with finite differences for the elastic wave equation. Geophysics 1987, vol. 52, pp. 483-501.

[8] Gazdag I.: Modeling of the acoustic wave equation with transform methods. Geophysics 1981, vol. 46, pp. 855-860.

[9] Jastram C., Tessmer E.: Elastic modeling on a grid with vertically varying spacing. Geophysical Prospecting 1994, vol. 42, pp. 357-370.

[10] Kelly K. R., Ward R., Treitel S., Alford R.: Synthetic seismograms. A finite difference approach. Geophysics 1976, vol. 41, pp. 2-27.

[11] Kosloff D., Filho Q., Tessmer E., Behle A.: Numerical solution of the acoustic and elastic wave equations by a new rapid expansion method. Geophysical Prospecting 1989, vol. 37, pp. 383-394.

[12] Kostecki A., Polchlopek A., Zulawinski K.: Odwzorowanie struktur wglebnych w osrodkach anizotropowych metoda migracji sejsmicznej. Prace Naukowe Instytutu Nafty i Gazu 2013, nr 191.
[13] Kostecki A., Zulawinski K.: Modeling of zero-offset time sections in TTI (Tilted Transverse Isotropy) media by pseudospectral method. EAGE Conference 2013, Extended Abstracts, Petersburg.

[14] Kostecki A., Zulawinski K.: Modelowanie i migracja sekcji czasowych zero-offsetowych w osrodkach TTI metoda pseudospektralna. Nafta-Gaz 2014, no. 12, pp. 855-860.

[15] Kostecki A.: Tilted Transverse Isotropy. Nafta-Gaz 2011, no. 11, pp. 769-776.

[16] Loventhal D., Lu L., Robertson R., Sherwod I.: The wave equation applied to migration. Geophysical Prospecting 1976, vol. 24, pp. 380-399.

[17] Marfurt K.: Accuracy of finite-difference and finite-element modeling of the scalar and elastic wave equations. Geophysics 1984, vol. 49, pp. 533-549.

[18] Thomsen L.: Weak elastic anisotropy. Geophysics 1986 , vol. 51, no. 10, pp. 1954-1966.

[19] Tsingas C., Vafidis A., Kanasewich E.: Elastic wave propagation in transversely isotropic media using finite differences. Geophysical Prospecting 1990, vol. 38, pp. 933-949.

[20] Virieux J.: P-SV wave propagation in heterogeneous media: Velocity-stress finite-difference method. Geophysics 1986, vol. 51, pp. 889-901.

[21] Zhou H., Zhang G., Bloor R.: An anisotropic acoustic wave equation for VTI media. 68th Annual International Conference EAGE 2006, Extended Abstracts.

[22] Zhou H., Zhang G., Bloor R.: An anisotropic acoustic wave equation for modeling and migration in 2D TTI media. 76th Annual International Meeting SEG 2006, Expanded Abstracts 25, pp. 194-198.

[23] Zhu J., Dorman J.: Two-dimensional, three-component wave propagation in a transversely isotropic medium with arbitrary-orientation - finite-element modeling. Geophysics 2000 , vol. 65 , 934-942.

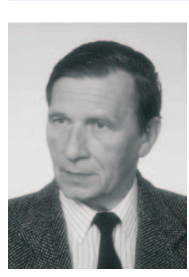

Prof. dr hab. Eng. Andrzej Kostecki

Full Professor

Oil and Gas Institute - National Research Institute

ul. Lubicz 25 A

31-503 Kraków

E-mail: andrzej.kostecki@inig.pl

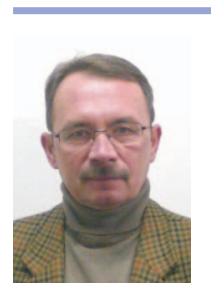

Krzysztof ŻUŁAWIŃSKI M.Sc. Eng.

Senior Technical Research Specialist

Seismic Department

Oil and Gas Institute - National Research Institute

ul. Lubicz 25 A

31-503 Kraków

E-mail: krzysztof.zulawinski@inig.pl 